\title{
Malignant Transformation of Grade II Ependymoma in a 2-Year-Old Child: Case Report
}

\author{
Şule Sarıkafa ${ }^{1}$ Suat Erol Çelikk ${ }^{1}$ Enver Yarikkaya ${ }^{2}$ \\ ${ }^{1}$ Department of Neurosurgery, Okmeydanı Training and Research \\ Hospital, Istanbul, Turkey \\ 2 Department of Pathology, Okmeydanı Training and Research \\ Hospital, Istanbul, Turkey
}

Ayşe Sayılgan ${ }^{2}$

J Neurol Surg Rep 2015;76:e151-e155.

\begin{abstract}
Keywords

- brain

- central nervous system

- ependymoma

- malignant transformation

- neoplasm
\end{abstract}

\author{
Address for correspondence Suat Erol Çelik, Department of \\ Neurosurgery, Okmeydanı Training and Research Hospital, Darulaceze \\ Caddesi, Şişli, Istanbul 34384, Turkey \\ (e-mail: suaterolcelik@yahoo.com; suatmd@gmail.com).
}

\section{Introduction}

Brain tumors are the second most frequent cause of childhood malignancy after hematologic disorders. Ependymomas are relatively rare neuroepithelial tumors and account for 3 to $7 \%$ of all central nervous system tumors. The incidence of ependymomas is more frequent in children, and $50 \%$ occur in children $<5$ years of age. Infratentorial locations of ependymomas are more frequent in infants and childhood, whereas supratentorial ependymomas are more often seen in adults. ${ }^{1}$ Ependymal tumors are closely related to the ventricular system and central canal. They can be observed extradurally in the sacral region and in the subarachnoidal space of the hemispheres. The most common location for infratentorial ependymomas is inside the fourth ventricle. ${ }^{2}$
The clinical signs and symptoms of intracranial ependymomas depend on the location, size of the tumor, and the age of the patient. Ependymomas may be large at the time of presentation because they grow slowly. The symptoms in posterior fossa ependymomas are related to increased intracranial pressure from hydrocephalus caused by obstruction of the fourth ventricle. Nausea, headache, and vomiting are presenting symptoms. Ataxia, dizziness, hemiparesis, and visual disturbance may add to the clinical picture. ${ }^{1,2}$

The current imaging protocol for the diagnosis is magnetic resonance imaging (MRI). On T1-weighted slices, ependymomas are hypointense when compared with brain parenchyma. On T2-weighted slices, these are isointense with gray matter. The most characteristic finding on MRI is a downward extrusion of the tumor through the foramen of Magendie into
License terms

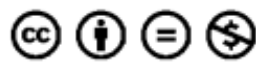

received

November 24, 2014 accepted after revision February 22, 2014 published online April 27, 2015
DOI http://dx.doi.org/ 10.1055/s-0035-1549311. ISSN 2193-6366. (c) 2015 Georg Thieme Verlag KG Stuttgart · New York 
the cervical subarachnoid cervical space or through the foramen of Luschka into the cerebellopontine cistern. ${ }^{3,4}$ This presentation highlights the requirement for close follow-up of grade II ependymomas for anaplastic transformation.

\section{Case Report}

A 1-year-old boy presented with visual disturbances. His conscious level was normal, and he responded to painful stimuli with crying. He was oriented and followed colorful objects. His eyes were open spontaneously; however, his left eye was looking at medial and downside, and his left eye gaze was limited to upside and lateral. He had no motor deficits. He was not walking, but he had normal head and neck movements. An infratentorial brain tumor in the median and right cerebellar area was found on contrast MRI. The tumor was totally removed by surgical approach via a suboccipital craniotomy. After surgery, hydrocephalus developed, and a ventriculoperitoneal shunt was inserted. Pathologic diagnosis was grade II ependymoma. In the following months there was no recurrence on control MRIs (-Fig. 1).

The patient presented with vomiting and visual disturbance to the pediatric emergency department 12 months later. He had no neurologic deficits. A new contrast MRI showed the recurrence of tumor in the same location. The patient was transported to neurosurgery, and a reoperation was performed. On the second operation, the tumor was hard to aspirate with the Cavitron Ultrasonic Surgical Aspirator (Sonoca 400, Söring GmbH, Quickborn, Germany) and lower cranial nerves. Only subtotal extirpation could be achieved (-Fig. 2). However, surgical specimens showed upgrading of the malignancy. The recurrent tumor showed anaplastic features such as nuclear pleomorphisms and necrosis with pseudopalisading (-Fig. 3).

\section{Discussion}

Bailey and Cushing recognized ependymomas as an independent entity in their first brain tumor classification in 1926. Variants were subsequently established. The most recent World Health Organization (WHO) classification identified four variants of ependymal tumors in addition to three grades of malignancy., 5 These four variants are myxopapillary ependymoma, subependymoma, tanycytic ependymoma, and clear cell ependymoma. $3,6,7$

Myxopapillary ependymomas and subependymomas are slow-growing tumors classified as grade I. Both lesions are easily recognizable lesions; therefore grading is not debatable. In accordance with the last WHO classification, grade III ependymomas have "increased cellularity and brisk mitotic activity, often associated with microvascular proliferation and pseudo palisading necrosis." Grade II relates to ependymomas that lack these malignant features. - Table $\mathbf{1}$ shows the classification scheme of ependymomas. Histologic grade is the most important prognostic factors of the pediatric ependymoma. The high-grade variant is both locally invasive and may show subarachnoid dissemination. Merchant et al summarized the histologic characterization and the outcome of 50 patients. Their results showed that poor clinical results paralleled histopathologic grade. ${ }^{8}$

The outcome of children with intracranial ependymomas has improved significantly during the last few years. Otherwise, their prognosis is not better than other pediatric brain tumors. In infants, they have typically poorer outcome. Recent reports demonstrate a 5-year overall survival rate not more than 40 to $65 \%$ in children with intracranial ependymomas. $^{9-12}$ Pediatric Oncology Group findings suggest that the poor survival estimates frequently reported for infants are most likely related to the higher incidence of infratentorial tumors, the lower rate of complete resection, and the delay of the administration of radiation therapy. ${ }^{13}$

The extent of surgical resection appears to be the other important prognostic factor in outcome for children with intracranial ependymomas. In patients with complete removal, 5-year survival is 67 to $80 \%$; 5-year progression-free survival is 51 to $75 \% .^{14-16}$

Studies have shown that patients with ependymoma who receive radiation therapy have a better outcome than who are not treated with irradiation. ${ }^{17,18}$ However, there is no standard protocol for optimal management for children with intracranial ependymomas. Total/near-total surgical resection with an acceptable neurologic outcome combined with postoperative radiation therapy is the current treatment modality. Immediate postoperative irradiation is not widely accepted in the treatment of children $<3$ years of age. Optimal radiation dose remains controversial. Most recent reports recommend local field radiation therapy. Stereotactic radiosurgery has been applied to manage recurrent or residual intracranial tumor in some institutions. Some reports described that adjuvant chemotherapy did not influence survival of patient with anaplastic ependymomas. ${ }^{18-20}$

The most common location for infratentorial ependymoma is within the fourth ventricle. The selected surgical approach may be a suboccipital craniotomy with or without C1 laminectomy depending on the extension of the tumor in the cervical region. Surgical resection appears to the most important prognostic factor; therefore the best effort to perform total or near-total resection should be made. ${ }^{21,22}$

In conclusion, the ependymomas of the children are difficult to control, and surgical removal remains the mainstay of the treatment. Despite a gross total resection, the tumor may regrow, and a second surgery might be necessary. Transformation to grade III anaplastic ependymoma is also possible for grade II cases. The correct grading of intracranial ependymomas may be difficult for the anaplastic variant because the common criteria for anaplasia are not completely reliable for all cases. ${ }^{13,22}$ Ependymomas in young infants have a worse prognosis than older children, so we need a grading scheme with a proven general ability to distinguish grades and to predict the evolution of individual cases. ${ }^{23}$ Also new radiation therapy techniques and chemotherapeutic agents need to be developed. Postoperative irradiation is not recommended in the treatment of grade II ependymomas for children $<3$ years of age. Total tumor removal should be attempted in the first operation. 

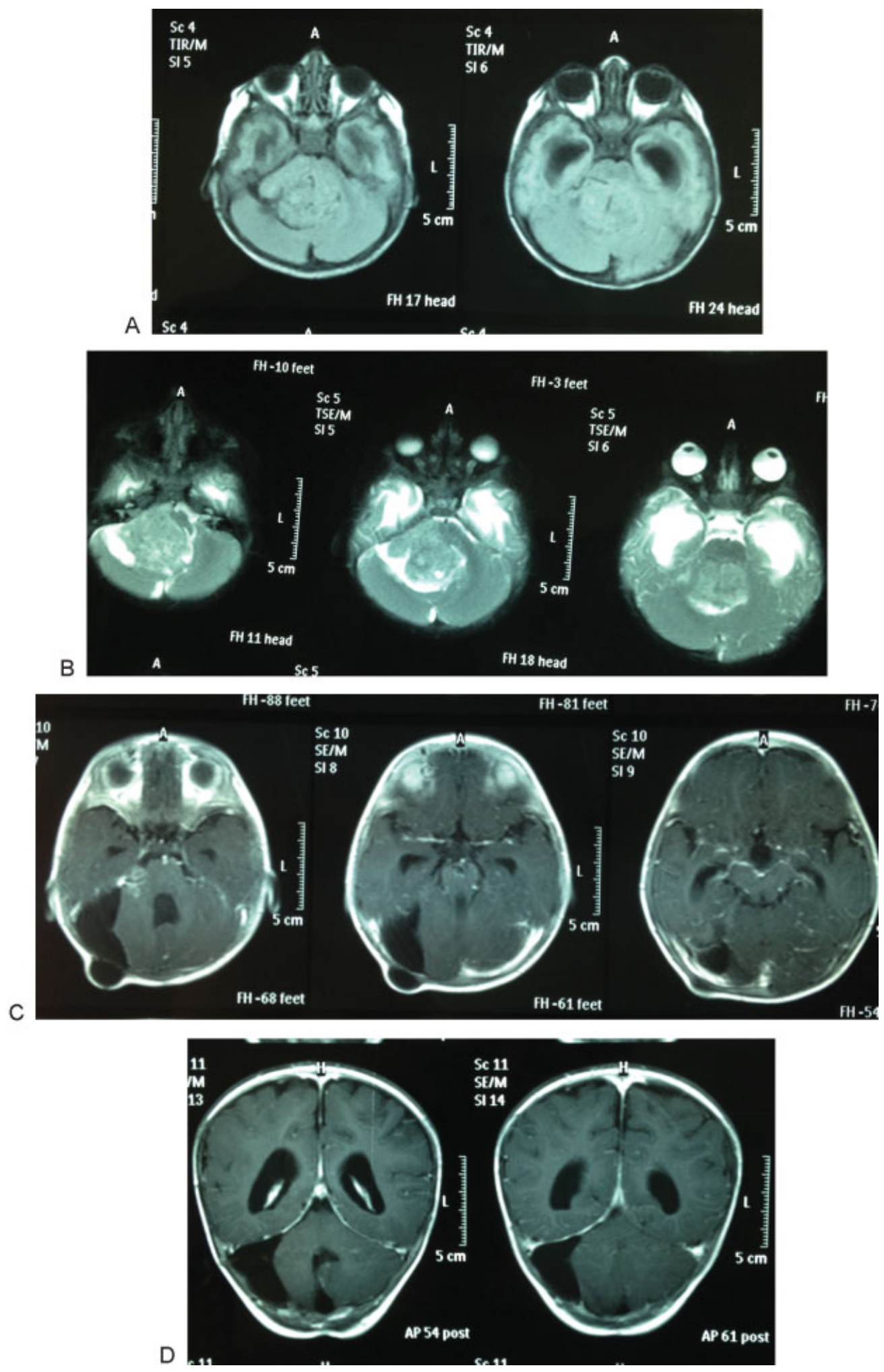

Fig. 1 Axial initial magnetic resonance imaging scans show posterior fossa mass filled in fourth ventricle (A) with nonhomogeneous slight contrast enhancement (B). Severe hydrocephalus can be seen with temporal horn filling secondary to the obstruction of the fourth ventricle. Postoperative axial (C) and coronal contrasted images (D) show complete resection of the mass with opening of the fourth ventricle and relaxation of the temporal horns. The shunt valve can be seen subcutaneously on axial images. 

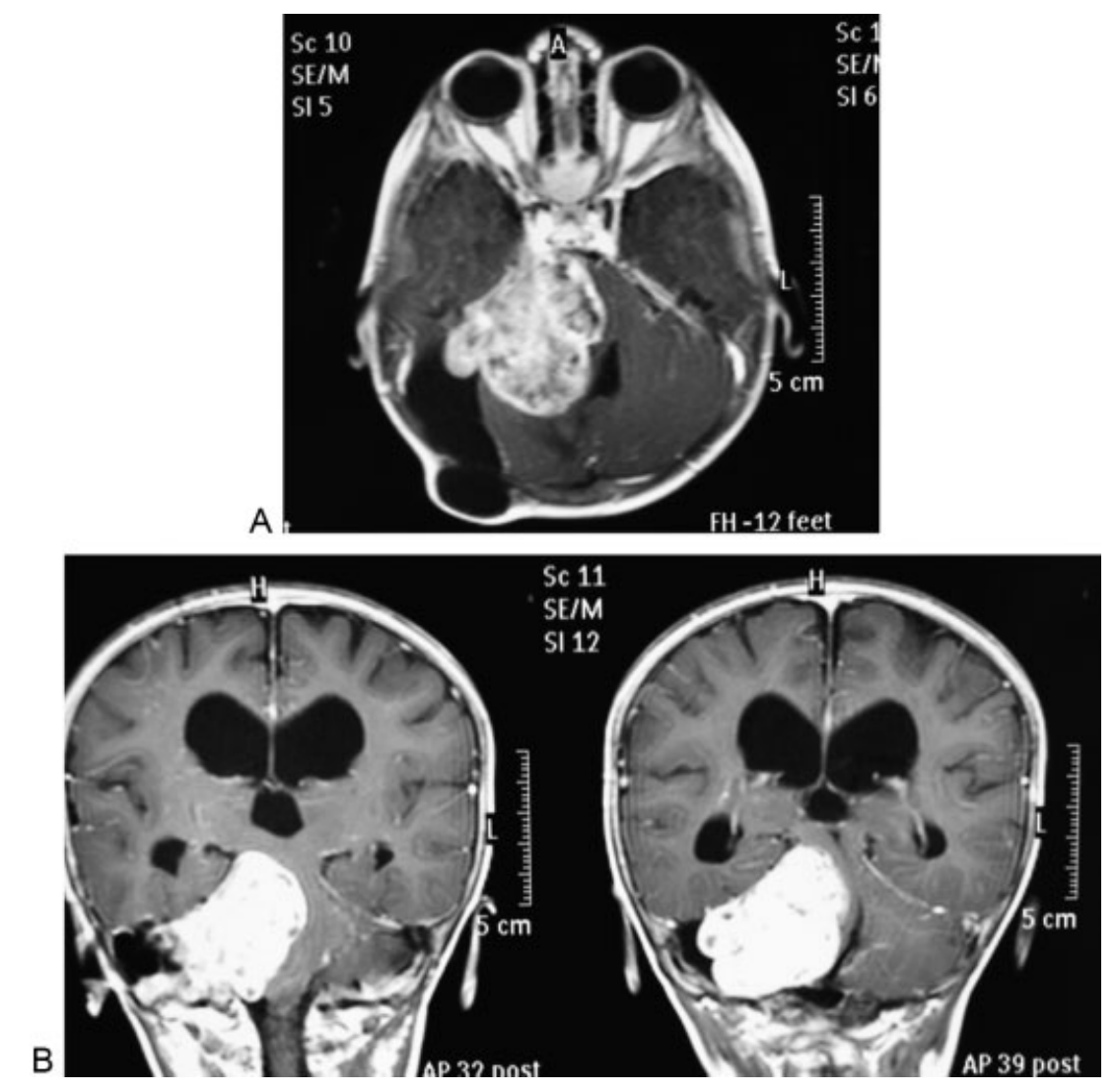

Fig. 2 Postcontrast axial (A) and coronal (B) images show regrowth of the mass lesion with strong contrast uptake. Fourth ventricle and brainstem compression with attachment of the tentorium can be seen.

A
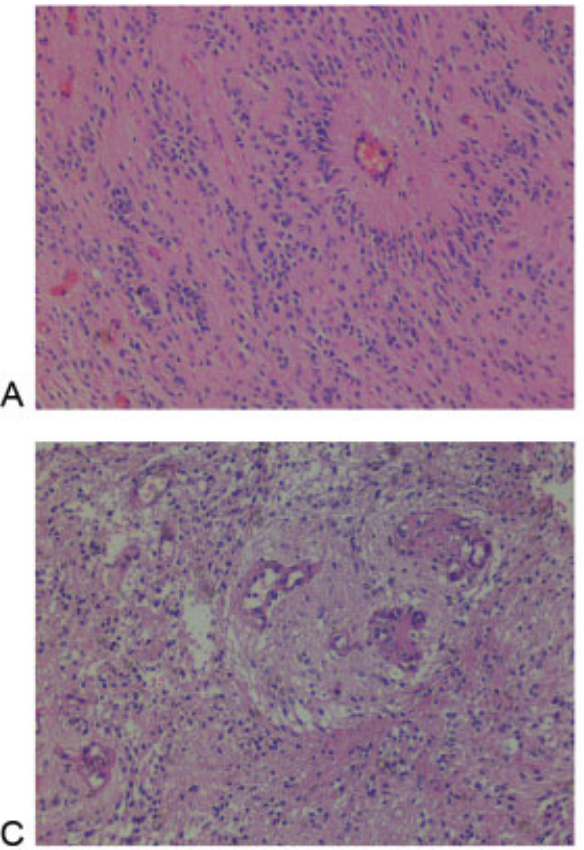
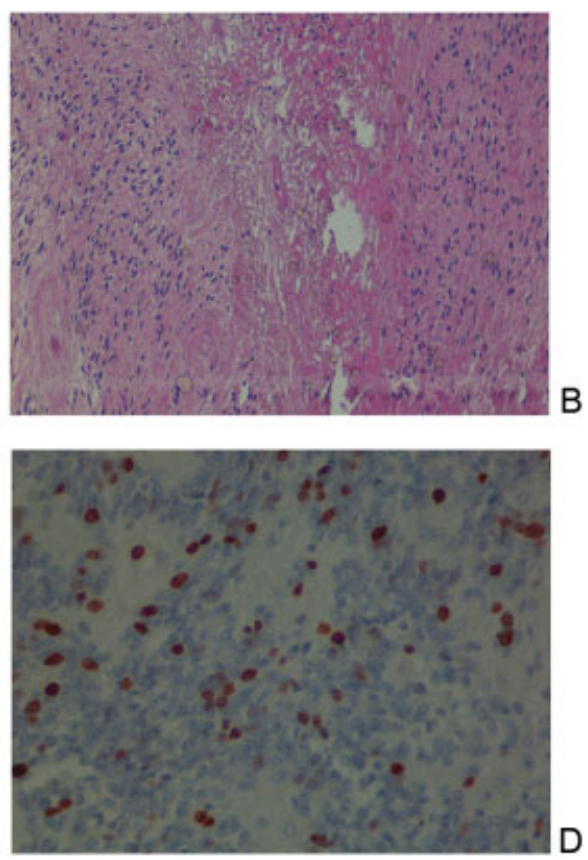

Fig. 3 Inıtial microscopic evaluation of the case after first operation. (A) Moderately cellular tumor composed of monomorphic cells with round to oval nuclei containing "salt and pepper" pattern of chromatin. Radially arranged ependymal cell processes become thinner toward the vascular wall leaving an acellular zone around the blood vessel, called "perivascular pseudorosette," a key histologic feature for ependymoma (hematoxylin and eosin $[\mathrm{H \& E}] \times 100)$. After the second operation $(\mathrm{B})$ abundant endothelial proliferation, microvascular proliferation, hypercellularity with nuclear hyperchromasia, pleomorphism, numerous mitoses, and pseudopalisading necrosis warrants a diagnosis of anaplastic ependymoma when seen throughout the lesion (H\&E $\times 200$ ). Moreover (C), focus of coagulative necrosis, nuclear pseudopalisading was prominent around the necrotic areas, tumor cells oriented closer to viable areas emphasizing anaplastic changes $(\mathrm{H} \& \mathrm{E} \times 200)$. Ki-67 immunolabeling index is an independent prognostic factor and accurate predictor of outcome in patients with intracranial ependymoma (D). The index was $10 \%$ in the first operation that increased to $35 \%$ for our case in this image $(\mathrm{Ki}-67 \times 200)$. 
Table 1 Classification of ependymal tumors

\begin{tabular}{|l|l|}
\hline Grade I & Including subependymoma and myxopapillary ependymoma \\
\hline Grade II & Corresponding to ependymoma \\
\hline Grade III & Comprising anaplastic ependymoma \\
\hline
\end{tabular}

\section{References}

1 McLaughlin MP, Marcus RB Jr, Buatti JM, et al. Ependymoma: results, prognostic factors and treatment recommendations. Int J Radiat Oncol Biol Phys 1998;40(4):845-850

2 Schiffer D, Giordana MT. Prognosis of ependymoma. Childs Nerv Syst 1998;14(8):357-361

3 Applegate GL, Marymont MH. Intracranial ependymomas: a review. Cancer Invest 1998;16(8):588-593

4 Lefton DR, Pinto RS, Martin SW. MRI features of intracranial and spinal ependymomas. Pediatr Neurosurg 1998;28(2):97-105

5 Gerszten PC, Pollack IF, Martínez AJ, Lo KH, Janosky J, Albright AL. Intracranial ependymomas of childhood. Lack of correlation of histopathology and clinical outcome. Pathol Res Pract 1996;192(6):515-522

6 Hamilton RL, Pollack IF. The molecular biology of ependymomas. Brain Pathol 1997;7(2):807-822

7 Merchant TE. Current management of childhood ependymoma. Oncology (Williston Park) 2002;16(5):629-642, 644; discussion 645-646, 648

8 Merchant TE, Haida T, Wang MH, Finlay JL, Leibel SA. Anaplastic ependymoma: treatment of pediatric patients with or without craniospinal radiation therapy. J Neurosurg 1997;86(6):943-949

9 Lyons MK, Kelly PJ. Posterior fossa ependymomas: report of 30 cases and review of the literature. Neurosurgery 1991;28(5): 659-664; discussion 664-665

10 Palma L, Celli P, Cantore G. Supratentorial ependymomas of the first two decades of life. Long-term follow-up of 20 cases (including two subependymomas). Neurosurgery 1993;32(2):169-175

11 Evans AE, Anderson JR, Lefkowitz-Boudreaux IB, Finlay JL. Adjuvant chemotherapy of childhood posterior fossa ependymoma: cranio-spinal irradiation with or without adjuvant CCNU, vincristine, and prednisone: a Children's Cancer Group study. Med Pediatr Oncol 1996;27(1):8-14

12 Rousseau P, Habrand JL, Sarrazin D, et al. Treatment of intracranial ependymomas of children: review of a 15-year experience. Int J Radiat Oncol Biol Phys 1994;28(2):381-386
13 Perilongo G, Massimino M, Sotti G, et al. Analyses of prognostic factors in a retrospective review of 92 children with ependymoma: Italian Pediatric Neuro-oncology Group. Med Pediatr Oncol 1997; 29(2):79-85

14 Foreman NK, Love S, Thorne R. Intracranial ependymomas: analysis of prognostic factors in a population-based series. Pediatr Neurosurg 1996;24(3):119-125

15 Horn B, Heideman R, Geyer R, et al. A multi-institutional retrospective study of intracranial ependymoma in children: identification of risk factors. J Pediatr Hematol Oncol 1999; 21(3):203-211

16 Sutton LN, Goldwein J, Perilongo G, et al. Prognostic factors in childhood ependymomas. Pediatr Neurosurg 1990-1991;16(2): 57-65

17 Robertson PL, Zeltzer PM, Boyett JM, et al. Survival and prognostic factors following radiation therapy and chemotherapy for ependymomas in children: a report of the Children's Cancer Group. J Neurosurg 1998;88(4):695-703

18 Needle MN, Goldwein JW, Grass J, et al. Adjuvant chemotherapy for the treatment of intracranial ependymoma of childhood. Cancer 1997;80(2):341-347

19 Souweidane MM, Bouffet E, Finlay J. The role of chemotherapy in newly diagnosed ependymoma of childhood. Pediatr Neurosurg 1998;28(5):273-278

20 Nazar GB, Hoffman HJ, Becker LE, Jenkin D, Humphreys RP, Hendrick EB. Infratentorial ependymomas in childhood: prognostic factors and treatment. J Neurosurg 1990;72(3):408-417

21 Healey EA, Barnes PD, Kupsky WJ, et al. The prognostic significance of postoperative residual tumor in ependymoma. Neurosurgery 1991;28(5):666-671; discussion 671-672

22 Mork SJ, Loken AC. Ependymoma: a follow-up study of 101 cases. Cancer 1977;40(2):907-915

23 Pollack IF, Gerszten PC, Martinez AJ, et al. Intracranial ependymomas of childhood: long-term outcome and prognostic factors. Neurosurgery 1995;37(4):655-666; discussion 666-667 